\title{
The Use of Demonstrative Pronoun and Demonstrative Determiner this in Upper-Level Student Writing: A Case Study
}

\author{
Katharina Rustipa ${ }^{1}$ \\ ${ }^{1}$ Faculty of Language and Cultural Studies, Stikubank University (UNISBANK) Semarang, Indonesia \\ Correspondence: Katharina Rustipa, UNISBANK Semarang, J1. Tri Lomba Juang No.1 Semarang 50241, \\ Indonesia. Tel: 622-4831-1668. E-mail: katrin_esde@yahoo.co.id
}

Received: January 20, 2015 Accepted: February 26, 2015 Online Published: April 23, 2015

doi:10.5539/elt.v8n5p158 URL: http://dx.doi.org/10.5539/elt.v8n5p158

\begin{abstract}
Demonstrative this is worthy to investigate because of the role of this as a common cohesive device in academic writing. This study attempted to find out the variables underlying the realization of demonstrative this in graduate-student writing of Semarang State University, Indonesia. The data of the study were collected by asking three groups of students (first semester, second semester, third semester students) to write an essay. The collected data were analyzed by identifying, classifying, calculating, and interpreting. Interviewing to several students was also done to find out the reasons underlying the use of attended and unattended this. Comparing the research results to those of the Michigan Corpus of Upper-level Student Paper (MICUSP) as proficient graduate-student writing was done in order to know the position of graduate-student writing of Semarang State University in reference to MICUSP. The conclusion of the research results is that most occurrences of demonstrative this are attended and these occurrences are stable across levels, similar to those in MICUSP. The reasons underlying the usage are to create unity, to build text and context relationship, to keep theme-rheme structure, to have variation. And the choice of using attended this or unattended this can be explained as a choice of maxim of manner or maxim of quantity proposed by Grice. It is suggested that a writing teacher review the theory how to write such as cohesion, unity, theme-rheme pattern in writing class since this will facilitate the writing process.
\end{abstract}

Keywords: demonstrative pronoun, demonstrative determiner, attended this, unattended this, MICUSP

\section{Introduction}

Writing competence facilitates professionals' and students' success in their career and in their study. In order to produce a coherent text, a writer needs to employ sufficient metadiscourse markers to explicitly organize their texts, for linking one part of a text to another (Rustipa, 2014, p. 44). It is likely that writing in English is still the hardest work for many Indonesian scientists (Rustipa, 2013, p. 41). Therefore, writing is a field worthy of investigation, ranging from genre, professional writing, academic writing, student writing, metadiscourse markers in order to come up with pedagogical significances. This study is also another attempt to contribute to writing pedagogy. It is aimed at investigating and describing a linguistic phenomenon of the use of metadiscourse marker this found in upper-level student writing. Romer and Wulff (2010) call this term as attended vs. unattended this. Swales' study (2005) revealed the role of this as a common cohesive device in academic writing.

This case study searched the variable realization of the demonstrative pronoun this standing alone and the demonstrative determiner attended by a noun or noun phrase. Especially when occurred in initial position, the demonstrative is sometimes followed by a noun or noun phrase and sometimes not. It is a way of structuring sentence based on theme-rheme or given-new information pattern. And it is also a way of getting out of one sentence into another. It is likely that the writer's choice of one over the other variant is partly influenced by the Grice's maxims or cooperative principle.

The previous studies on demonstratives have been done by several researchers as follows. Oh's study (2001) as cited by Zaki (2011) revealed that the most critical factor guiding the writer's/speaker's choice of a demonstrative is the sense of calling the interlocutor's attention to something for a particular purpose.

Swales (2005) investigated 80 research articles from Hyland corpus. Based on the data analysis, it's found out that $64 \%$ of the occurrences of this were attended, while $36 \%$ others were unattended. Swales (2005) as cited by 
Romer and Wulff (2010) concludes that attended this tends to be preferred by writing professionals because it provides more clarity and provides recontextualization of the previous text.

Romer and Wulff (2010) explored the occurrences of attended and unattended this in Michigan Corpus of Upper-level Student Paper (MICUSP). Thus, it's a MICUSP-based case study of demonstrative this. The research results revealed that $72.67 \%$ out of 9,411 occurrences of this were attended, while $27.33 \%$ others were unattended. Romer's and Wulff's study had inspired the current study which was more likely a replication of their study since both of them investigated upper-level student writing.

Michigan Corpus of Upper-level Student Paper (MICUSP) compiled written discourse of highly proficient, advanced-level native and non-native speaker student writers. MICUSP were written by final year undergraduate and first to third year graduate students who obtained an A grade for their paper (Romer and Wulff, 2010). Thus, MICUSP is a standard proficient upper-level student writing that can be used as a benchmark. Based on this reason, I compared the result of the current study with that of Romer's and Wulff's study. Therefore, the current study was aimed at finding out 1) the occurrences of demonstrative pronoun and demonstrative determiner this of graduate-student writing of Semarang State University, 2) describing the occurrences in reference to Michigan Corpus of Upper-level Student Paper (MICUSP).

\section{Review of Related Literature}

In English writing, this can function as a demonstrative pronoun (unattended this) or as a demonstrative determiner (attended this). When this is immediately followed by a noun or noun phrase and so has an associated nominal, it is often referred to as attended this. Whereas when this is not immediately followed by a noun or noun phrase and so it stands alone, it is often referred to as unattended this (Geisler et al., 1985 as cited by Romer \& Wulff, 2010).

Zaki (2011) explains that demonstratives play a crucial role to instruct the interlocutor to maintain or create attention to the intended referent. Therefore, demonstratives are often termed as demonstrative references because they are actually referring expressions.

Demonstratives are parts of cohesive devices to build cohesive and coherent texts. The use of cohesive devices is partly influenced by cooperative principle postulated by Grice (1975). Based on this consideration, cohesion, reference, demonstrative, cooperative principle will be presented and clarified in this section.

\subsection{Cohesion}

According to Halliday and Hasan, whether a set of sentences constitutes a text or not depends on cohesive relationship within and between sentences (1976, p. 15). Cohesion deals with the bottom up elements that help generate texts, accounting for how pronouns, demonstrative, articles and other markers signal textual co-reference in written and oral discourse. It also accounts for how conventions of substitution and ellipsis allow speakers/writers to indicate co-classifications and to avoid unnecessary repetition. The use of conjunctions (e.g. but, however) to make explicit links between propositions in discourse is another important cohesive tie (Halliday \& Hasan, 1989, p. 15). Cohesion, then, is the surface links between sentences of a text that holds the text together; and the links between sentences are displayed in terms of metadiscourse markers/cohesive devices. This cohesive relationship in a text is referred to as texture. Concerning the concept of cohesion, some scholars state as follows. Mey (2001, p. 133) states: "Cohesion is the way words formally hang together in sentences and the like, coherence is content-based connectedness between the words that make them produce sense." Stubb (1983, pp. 126-127) says "Cohesion has to do with relations between surface linguistic form, whereas coherence refers to relations between communicative acts." While Halliday and Hasan (1976, p. 4) state "Cohesion occurs where the interpretation of some elements in the discourse is dependent on that of another. The one presupposes the other, in the sense that it cannot be effectively decoded except by recourse to it. When this happens, a relation of cohesion is set up, and the two elements, the presupposing and the presupposed, are thereby at least potentially integrated into a text."

From the definitions above, it is clear that cohesion establishes local relations between syntactic items. And these relations are displayed with cohesive devices. They are devices to build in a text, and can be divided into five groups: reference, substitution, ellipsis, conjunction, and lexical (Halliday \& Hasan, 1976, p. 13; Brown \& Yule, 1983, p. 191).

\subsection{Reference}

Reference refers to how the writer/speaker introduces participants and then keeps track of them once they are in the text. The two important concepts in reference are the referring expressions and referents. Referring expressions are words which are used to refer to other words or things, whether they are in the text or outside the 
text, while the word referred to is called referent. If the referring expression is used to refer to something outside the text, it is called exophora. On the other hand, if it is used to refer to the words in the text it is called endophora. The concept of endophora is classified into anaphora and cataphora. Anaphora is the referring expression which is used to refer backward, i.e. to words which have been used in the text, while cataphora refers forward to words coming later. In short, exophoric demonstratives are situational, i.e. to point to an entity in the physical environment (usually accompanied by pointing gesture) while endophric demonstratives are non situational, i.e. to point to anything else in the previous or following text at the moment (part of the text that is currently being produced). The reference can be subdivided into: personal pronouns (pronominals), demonstrative reference, comparative reference.

Personal reference (pronominals) is reference by means of category of person/noun which is classified into pronouns/personal pronouns (I, you, he, she, we, they, it, one), possesive determiners (my, your, his, her, our, their, its, one's), possesive pronouns (mine, yours, his, hers, ours, theirs, it). Comparative reference is indirect reference by means of identity or similarity. The words used to express comparative reference are the same, similar, such, different, equal, likewise, so, better, more, less, otherwise. Demonstrative reference is the reference by means of location, time, on the scale of proximity consisting of nominative demonstrative (this, that, these, those), circumstantial demonstratives (there, here, now, then), and definite article "the".

\subsection{Demonstratives}

A demonstrative is a word used to refer to some other entity associated with a notion of relative distance (proximal/distal). Grammatically, it can function as a determiner or as a pronoun. The reference of a demonstrative is contextually motivated by a writer/a speaker and contextually inferred by a reader/a hearer. Pragmatically, demonstratives play an important role in the organization of information flow in a text. They can reactivate the previously mentioned referents with or without new information. But they can also introduce new referents in a text. They can refer to what a writer/a speaker is explicitly writing/saying and to what a writer/a speaker is implicitly writing/saying (Zaki, 2011). Thus, demonstratives are referring expressions whose interpretations depend on the contexts and inference. And the choice in using demonstratives should be carefully done in order for achieving the communicative goal. Because of this, Enfield (2003) argues that demonstratives are one of the great puzzles of linguistic science.

Grice (1989) explains that communication is not only a matter of encoding and decoding, but it is also more than that, it needs inference from the interlocutor. Yourgrau (1990) adds that to find out the intended referents of demonstratives, an interlocutor needs to have context sensitivity because demonstratives are context-dependent expressions.

Halliday and Hasan (1976) differentiate English demonstratives based on semantic, grammatical, and semantic features. Semantically, demonstratives are distinguished into proximal and distal. Grammatically, demonstratives are distinguished into singular and plural. While, syntactically demonstratives are distinguished into modifier (demonstrative determiner) and head (demonstrative pronoun). This study focuses on investigating demonstrative determiner and demonstrative pronoun this. Based on this reason, demonstrative determiner and demonstrative pronoun will be further discussed in this section.

There are differences in meaning between demonstratives functioning as modifier and head. The latter is more like a personal pronoun. Examples: 1) That garden seems bigger (modifier/determiner); 2) That is a big garden (head/pronoun). In Standard English, this is more specific than that since this has the speaker as its point of reference while that has no particular reference point, it is only interpreted as not this (Halliday \& Hasan, 1976).

Himmelman (1996) classifies four major categories of demonstrative use, i.e. situational, discourse deictic, tracking, and recognitional. A situational demonstrative is used to refer directly to referents or entities in the situation of speech event. A recognitional demonstrative involves the retrieval of personally shared experience. A discourse deictic demonstrative refers to the result of processing a part of discourse. Moreno (2003, p. 116) states that it refers to the meaning derived from larger fragments of text, e.g. sentences, clauses. The four sentences below exemplify the four demonstrative uses.

1) Is this your house? (situational)

2) A lot of corruptors have been sent to jail. That satisfies society. (discourse deictic)

3) The implementation of 2013 curriculum was delayed by the government. This delay got various reactions from education practitioners. (tracking)

4) Do you still keep that purse that I bought you last year? (recognitional) 
The first and the second demonstratives are demonstrative pronoun (unattended), while the third and fourth demonstratives are demonstrative determiner (attended).

Huang (2000) as cited by Zaki (2011) explains that the writer/speaker, in deciding a particular referring form, has to make sure that it can serve the interlocutor to identify the intended referent.

\subsection{Cooperative Principle}

Writers/speakers try to be optimally relevant to the interlocutors by choosing the expression, word, etc. that could be processed and comprehended easily by the interlocutor in order that they can achieve their communicative purpose. Thus, in order to be successful in communication, cooperation between the writer/speaker and the interlocutor is needed.

Concerning the cooperation between a writer and a reader, Storrer $(2002$, p. 1) explains as follows. The author focuses on the models of coherence design on discourse production. These models describe the strategies the authors use in order to guide and promote the process of coherence building done by the readers. On the contrary, the reader focuses on the models of coherence building. These models describe how readers build coherent knowledge structures while processing text. Thus, an author should design a text in such a way that the addressee may detect the relationships linking individual text constituents.

Grice (1975) proposes that participants in a communication obey a cooperative principle (CP). Hamadi and Muhammed (2009) explain that according to Gricean theory, there are four basic guidelines or rules (maxims) which model the efficient and effective use of language. Thus, CP comprises four maxims.

Levinson (1983, pp. 101-102) states that the four maxims are maxims of quantity, quality, relevance, and manner. These maxims refer to the amount of information, truthfulness, relatedness, brevity and clarity.

Grice (1975) regards the four maxims as universal principles although some researchers as cited by Hamadi and Muhammed (2009) regard them as culture bound, especially maxims of quantity and relevance. It is said that employing CP will benefit the participants. However, Grice suggests that there are cases when these guidelines may be violated. And the violation will not breakdown the interaction. Leech (1980) explains that interlocutors try to understand contributions to violated maxims as informative, truthful, relevant, and clear. Once these contributions are broken, the interlocutors try to interpret or search for inferences or conversational implicatures. In the following, the four maxims will be explained (sources: Levinson, 1983; Leech, 1980).

Maxim of quantity refers to the way the communicators try to make their contribution as informative as is required, not more or less. Maxim of quality is related to the way the communicators try to communicate only what they believe to be true. Maxim of relevance means that the participants need to give relevant contribution to a particular exchange. Maxim of manner means that the communicator's contribution should be clear, brief, direct, to the point.

\section{Method}

This current study is a case study of demonstrative pronoun and demonstrative determiner this or attended and unattended this in graduate-student writing of Semarang State University, Indonesia. It is aimed at explaining the phenomenon of the use of demonstrative this by graduate students of Semarang State University. Specifically, the objectives of the study are to find out 1) the occurrences of demonstrative pronoun and demonstrative determiner this in graduate-student writing of Semarang State University, 2) describing the occurrences in reference to Michigan Corpus of Upper-level Student Paper (MICUSP).

This study is descriptive and qualitative in nature. Simple quantification was done in this study to support the description. The demonstrative pronoun and demonstrative determiner this or attended and unattended this in graduate-student writing of Semarang State University were identified, analyzed and described. The research subjects/participants, the collection and the analysis of the data in this research can be illustrated below.

\subsection{Participants}

The participants of the study were the first and the second-semester graduate students of Semarang State University academic year 2013/2014, and the third-semester graduate students of Semarang State University academic year 2014/2015. The students major in the English language education.

\subsection{Method of Data Collection}

The data of the study were collected by asking the students to write an essay for 90 minutes in the classroom. In order that the essays reflected their writing competence, while they were writing they were not allowed to consult dictionary, to use computer, and they were also not allowed to access internet. There were three groups 
of students participating in this study. They were 1) group 1, the first-semester students of Semarang State University academic year 2013/2014, 2) group 2, the second-semester students of Semarang State University academic year 2013/2014, 3) group 3, the third-semester students of Semarang State University academic year 2014/2015. The data collector was the researcher herself who was their part-time lecturer. The way of eliciting the data was as follows:

In November 2013, each student in group 1 (consisting of 29 students) was asked to write an essay on a piece of paper by choosing one of the provided topics: 1) The importance of English in this global era, 2) English language teaching and learning. They wrote for 90 minutes without the teacher's help and without consulting the dictionary. They were obliged to write minimally 5 paragraphs, but the teacher didn't limit the number of words. In May 2014, each member in group 2 (consisting of 27 students) were asked to write an essay on a piece of paper by choosing one of the provided topics: 1) Giving a lot of homework to the students, 2) Character building education. They wrote in the same way as group 1 did. And in November 2014, each member in group 3 (consisting of 25 students) were asked to write an essay on a piece of paper by choosing one of the provided topics: 1) Reality shows on television, 2) Communicating via e-mail or instant messaging. They wrote with the same rule as group 1 and $2 \mathrm{did}$. Afterwards, the researcher chose 15 essays from each group. The essays chosen were the ones obtaining grade A. Then, 3 X 15 essays $=45$ essays were used as the data of the study.

\subsection{Method of Data Analysis}

After the data were collected, manual analysis was done in this study. The steps of analyzing the data were:

1) Identifying

The demonstrative pronoun and demonstrative determiner this of graduate-student writing of Semarang State University were identified.

2) Classifying and calculating.

The demonstrative pronouns and demonstrative determiners were classified and calculated.

3) Interpreting.

The results of the calculation and classification were analyzed and interpreted.

4) Comparing

The results of the three group analysis were compared to each others. Then, the results of the whole analysis were compared with those of MICUSP.

5) Interviewing

Interview to five students from each group was done to find out their reasons for using attended and unattended this in their writing, and the reasons underlying their preference for the choice of using attended this to unattended this or vice versa. The questions for interview were: 1) Why did you use attended and unattended this in your writing? 2) Why did you prefer to use attended this to unattended this? 3) Why did you prefer to use unattended this to attend this?

\section{Findings and Discussion}

\subsection{Findings}

After identifying and calculating the occurrences of demonstrative this, it was found out that the average use of demonstrative pronoun this was $32 \%$, with the distribution: the first-semester students' average use of demonstrative pronoun this was 35\%, the second-semester students' average use of demonstrative pronoun this was $30 \%$, while the third-semester students' average use of demonstrative pronoun this was $31 \%$.

The average use of demonstrative determiner this was $68 \%$, with the distribution: the first-semester students' average use of demonstrative determiner this was $65 \%$, the second-semester students' average use of demonstrative determiner this was $70 \%$, while the third-semester students' average use of demonstrative determiner this was $69 \%$.

Overall, the occurrences of the demonstrative pronouns and demonstrative determiners this used by graduate-students of Semarang State University can be summarized in the following tables. 
Table 1. Distribution of attended and unattended this in graduate-student writing of Semarang State University

\begin{tabular}{lllllllll}
\hline $\begin{array}{l}\text { Occurrences in } \\
\text { graduate students' }\end{array} 1^{\text {st }}$ writing & \multicolumn{2}{l}{$\begin{array}{l}\text { Occurrences in } \\
\text { graduate students' writing }\end{array}$} & $\begin{array}{l}\text { Occurrences in } \\
\text { graduate students' }\end{array} 3^{\text {rd }}$ writing \\
\hline No. & $\begin{array}{l}\text { Attended } \\
\text { this }\end{array}$ & $\begin{array}{l}\text { Unattended } \\
\text { this }\end{array}$ & No. & $\begin{array}{l}\text { Attended } \\
\text { this }\end{array}$ & $\begin{array}{l}\text { Unattended } \\
\text { this }\end{array}$ & No. & $\begin{array}{l}\text { Attended } \\
\text { this }\end{array}$ & $\begin{array}{l}\text { Unattended } \\
\text { this }\end{array}$ \\
\hline 1 & 4 & 2 & 16 & 5 & 2 & 31 & 3 & 1 \\
2 & 4 & 2 & 17 & 4 & 2 & 32 & 3 & 1 \\
3 & 3 & 1 & 18 & 5 & 3 & 33 & 4 & 2 \\
4 & 4 & 2 & 19 & 3 & 1 & 34 & 5 & 2 \\
5 & 5 & 3 & 20 & 4 & 2 & 35 & 4 & 3 \\
6 & 3 & 2 & 21 & 4 & 2 & 36 & 5 & 2 \\
7 & 4 & 3 & 22 & 4 & 2 & 37 & 4 & 2 \\
8 & 3 & 2 & 23 & 3 & 1 & 38 & 5 & 2 \\
9 & 5 & 2 & 24 & 5 & 2 & 39 & 4 & 2 \\
10 & 3 & 1 & 25 & 5 & 2 & 40 & 4 & 2 \\
11 & 3 & 1 & 26 & 5 & 1 & 41 & 5 & 2 \\
12 & 4 & 2 & 27 & 5 & 2 & 42 & 4 & 2 \\
13 & 3 & 2 & 28 & 3 & 1 & 43 & 4 & 2 \\
14 & 5 & 3 & 29 & 4 & 2 & 44 & 3 & 1 \\
15 & 3 & 2 & 30 & 4 & 2 & 45 & 5 & 2 \\
\hline Total & 56 & 30 & & 63 & 27 & & 62 & 28 \\
\hline
\end{tabular}

Table 2. Percentage of attended and unattended this in graduate-student writing of Semarang State University (per level)

\begin{tabular}{|c|c|c|c|c|c|}
\hline \multirow{3}{*}{ Student level } & \multicolumn{2}{|c|}{ Unattended this } & \multicolumn{2}{|l|}{ Attended this } & \multirow{3}{*}{ Total } \\
\hline & \multicolumn{2}{|l|}{ this } & \multicolumn{2}{|l|}{ this + noun } & \\
\hline & Occurances & $\%$ & Occurances & $\%$ & \\
\hline $1^{\text {st }}$ semester graduate students & 30 & $34.9 \%$ & 56 & $65.1 \%$ & 86 \\
\hline $2^{\text {nd }}$ semester graduate students & 27 & $30 \%$ & 63 & $70 \%$ & 90 \\
\hline $3^{\text {rd }}$ semester graduate students & 28 & $31.1 \%$ & 62 & $68.9 \%$ & 90 \\
\hline Average & 28 & $32 \%$ & 60 & $68 \%$ & \\
\hline
\end{tabular}

Table 3. Overall percentage of attended and unattended this in graduate-student writing of Semarang State University

\begin{tabular}{lllll}
\hline \multirow{2}{*}{ Student level } & \multicolumn{2}{l}{ Unattended this } & \multicolumn{2}{l}{ Attended this } \\
\cline { 2 - 5 } & \multicolumn{2}{l}{ this } & \multicolumn{3}{l}{ this + noun } \\
\cline { 2 - 5 } & Occurances & $\%$ & Occurances & $\%$ \\
\hline $1^{\text {st }}$ semester graduate students & 30 & $35.3 \%$ & 56 & $30.9 \%$ \\
$2^{\text {nd }}$ semester graduate students & 27 & $31.8 \%$ & 63 & $34.8 \%$ \\
$3^{\text {rd }}$ semester graduate students & 28 & $32.9 \%$ & 62 & $34.3 \%$ \\
\hline Total & 85 & $100 \%$ & 181 & $100 \%$ \\
\hline
\end{tabular}




\subsection{Discussion}

The research findings showed that overall the average percentage of demonstrative determiner this or attended this $(68 \%)$ was higher than that of demonstrative pronoun this or unattended this $(32 \%)$. These research findings are similar to those of Romer's and Wulff's study (2010) investigating Michigan Corpus of Upper-level Student Paper (MICUSP) and also similar to those of Swales' study (2005) investigating research articles from Hyland corpus. Romer's and Wulff's study (2010) found out that the average percentage of attended this was $73 \%$ while that of unattended this was $27 \%$. Swales' study (2005) revealed that $64 \%$ of the occurrences of this were attended, while $36 \%$ others were unattended.

The current research results found out that the ratio of the use of attended and unattended this was: $68 \%: 32 \%=$ 2:1. This is different from that of MICUSP, i.e. 3:1. However, the stability of distribution across levels is similar. Romer's and Wulff's study (2010) investigating MICUSP revealed that the ratio of the use of attended and unattended this was stable across levels (final year undergraduate, first-year graduate, second-year third-year graduate), i.e. 3:1. Similarly, this current study also revealed the stable ratio of the use of attended and unattended this across levels (first-semester, second-semester, third-semester graduate students), i.e. 2:1. This strengthens Romer's and Wulff's statement (2010): "the data do not suggest a development from higher to lower shares of attended this."

The occurrences of attended this in graduate-student writing of Semarang State University is fewer than those of MICUSP. This is perhaps because the teacher as the researcher limited the time for writing, i.e. 90 minutes for at least 5 paragraphs. Thus, perhaps they were economical in using words so that they could write more matters in the limited time. As stated above, Swales' study (2005) investigating experts' academic writing revealed that $64 \%$ of the occurrences of this were attended. It means that the occurrences of attended this in experts' academic writing were fewer than those of graduate-student writing of Semarang State University, i.e. 64\%:68\%. It was possibly because of the word limit that the authors of the research articles had to stick to.

The following are examples of sentences containing attended and unattended this taken from the data of this research.

1) English as a global language occurs in daily life situation. It is admitted that in this global era, learning English is a must (Text 1).

2) Teaching English as a foreign language is still hard to do. This is because most learners are influenced by their mother tongue (Text 10).

3) Giving a lot of homework will make benefit for education system. This benefit is parents will participate in their children education (Text 17).

4) The character building education is implemented in the new curriculum, curriculum 2013. This implementation has got pros and contras (Text 25).

5) The rapid development of technology nowadays provides us with easier way to communicate with others. However, this also has negative effects for human's life as social creature (Text 32).

6) Instead of its advantages, the presence of reality show in television also affects negatively in society. This negative effect must be considered seriously by the producer (Text 42 ).

To know the students' reasons for using attended and unattended this in their writing, the researcher interviewed fifteen students, five students from each group. Here are the answers of the first interview question: 1) Why did you use attended and unattended this in your writing?

The first reason is to create unity in the text, in order to make the text more coherent. Example: Internet is a communication tool that can be used almost for everything. This makes people depend on it too much (Text 45). This in the second sentence is called as a discourse deictic demonstrative referring to the meaning derived from the first sentence. Thus, the presence of this here links the meaning of the first sentence to the second sentence that makes the text more unified. In other words, this as a cohesive device is a tie between parts of a text. This is in line with Storrer's statement (2002) that the main feature of a text is unity, it should constitute a unified whole, from the beginning up to the end. What is meant by unity here is that the parts of the text hang together. There are ties among the parts of the text. Cohesion leads the addressees to detect the relationships linking of the individual text constituents that will support the readers/listeners in arriving at comprehension.

The second similar reason is to build text and context relationship as also stated by Swales (2005): it provides recontextualization of the previous text. And also it is in accordance with Halliday and Hasan (1989, p. 10) defining a text as "language that is functional". Functional means doing some job in some context, as opposed to 
isolated words or sentences. It is a product of its environment, a product of continuous process of choices in meaning. In other words, text has context. Every part of a text is at once constitutes a text in itself and context to the other text that is to come. Each part of the text creates the context within which the next bit of the text is interpreted. It is understood that in communicating meaning language users cannot convey everything at once. They can only convey one short stretch of the text at any time. From this perspective, a written discourse can be viewed as complex units of texts and meanings constantly evolving in the production process. A text consists of complex unit of texts, i.e. text at the moment, text at the past, text at the future. Text at the past and text at the future will become context for text at the moment (text that is currently being produced). Thus, there is relationship between what is written and what was written a moment ago. This interrelated feature between text and context is called unity. Example: Giving a lot of homework has been a debatable issue among educators. This matter has lead to discussion, seminar concerning the role of homework. The pros argue that homework can facilitate students to learn more about school subjects (Text 20). When the writer is producing the second sentence (the text at the moment), so the first and the third sentences become the context of the second sentence. And the word this matter links the text, i.e. the second sentence to the context, i.e. the first sentence.

The third reason is to keep theme-rheme structure in writing. This is in line with Butt (2001, p. 114) stating that theme is the starting point or signpost for a speaker, and rheme is a temporary destination. Usually the bit of the message that the writer or the speaker considers interesting or important comes in the rheme. While the first clause or clause complex in a text will probably contain new meanings, the thematic choices for the following clauses should not be unexpected. They should be connected with ideas that we have already met in the theme or rheme of a clause not too far before. Similarly, Romer and Wulff (2010) explain "Especially in phrase or sentence-initial position, the demonstrative, sometimes followed by a noun or noun phrase and sometimes not, is a key exponent of given-new information structuring." Swales (2005) states "it is also a way of getting out of one sentence into another." Example: The teachers introduce various vocabularies using gestures and various movements. This technique brings or creates an enjoyable classroom situation (Text 5). The theme of the first sentence is the teacher, while the rheme is introduce various vocabularies using gestures and various movements. The rheme in the first sentence becomes the theme in the second sentence this technique which is the other words from introduce various vocabularies using gestures and various movement. This is the way to get out from the first sentence into the second sentence.

The other reason is that the use of attended and unattended this in a text is for variation, to keep the style of writing. Only two students proposed this reason. Variation in the use of linguistic resources is needed to produce interesting writing.

Thus, to create unity, to build text and context relationship, to keep theme-rheme structure, to have variation are the reasons underlying graduate students of Semarang State University to use attended and unattended this. In the following, the students' reasons for preferring to use attended this to unattended this or vice versa will be discussed. In uncovering the reasons, the researcher asked the students: 1) Why did you prefer to use attended this to unattended this? 2) Why did you prefer to use unattended this to attended this?

The reasons for using attended this instead of unattended this are to guide the readers to find out the intended referent correctly so the intended referent is clear for the reader, to avoid ambiguity, to avoid misunderstanding, to make the text easy to be comprehended by the reader. In short, the reasons for the use of attended this are clarity. It refers to Gricean maxim of manner: 1) avoid obscurity of expression, 2) avoid unnecessary ambiguity, 3 ) be orderly. Thus, attended this is chosen because it clarifies reference unambiguously. This is also stated by Swales (2005): "attended this is preferred by professionals not only for its clarity but also because it provides an opportunity for higher level recontextualization of the previous text." Concerning how to use attended this, Romer and Wulff (2010) explains "When writers opt for attended this, the question arises which noun to select. One factor determining the variable presence of this seems to be the correctness of the noun phrase." Example: Before 2010, our education system focused on the cognitive and psychomotor achievement to create Indonesians who master science and technology so that it can increase Indonesian welfare and Indonesian position among the other developing countries. However, this education system seems to produce human resources who lack of good attitude (Text 29). The words this education system in the second sentence guide the reader to find out the referent mentioned in the first sentence and become the theme in the second sentence, i.e. education system focused on the cognitive and psychomotor achievement. The words this education here is called as tracking demonstrative.

The consideration for using attended this is to be efficient in using words. This is the application of Gricean maxim of quantity: 1) make your contribution as informative as required, 2) do not make your contribution more informative than is required. Thus, the choice of using attended this or unattended this can be explained as a 
choice of maxim of manner or maxim of quantity.

\section{Conclusions and Suggestions}

\subsection{Conclusions}

From the discussion above, some conclusions can be drawn. Demonstrative this used in graduate-student writing of Semarang State University is attended and unattended in nature. The use of attended this is more than that of unattended this. This usage is similar to that in Michigan Corpus of Upper-level Student Paper (MICUSP). The ratio of attended and unattended this occurring in graduate-student writing of Semarang State University is 2:1, while that in MICUSP is 3:1. These ratios tend to be stable across levels both in graduate-student writing of Semarang State University and in MICUSP. As stated in the previous section, MICUSP is a standard proficient upper-level student writing that can be used as a benchmark for other upper-level student writing. Thus, the similarities of the occurrences of demonstrative this used in graduate-student writing of Semarang State University and those used in MICUSP indicates that Semarang State University students are proficient in using demonstrative pronoun and demonstrative determiner this.

To create unity, to build text and context relationship, to keep theme-rheme structure, to have variation are the reasons underlying graduate students of Semarang State University to use attended and unattended this. And the choice of using attended this or unattended this can be explained as a choice of maxim of manner or maxim of quantity proposed by Grice.

\subsection{Suggestions}

Based on the conclusions above some recommendations are proposed. Since knowledge of how to write such as cohesion, unity, theme-rheme pattern facilitates the writing process, it is suggested that a writing teacher review the theory in writing class. And since the knowledge of Gricean cooperative principle, e.g. maxim of manner and maxim of quantity also facilitates the writing process, i.e. influences the writer in the word and/or grammar choice, it is suggested that this material also be taught in writing class, not only in Pragmatics class. For future researcher, it is recommended to investigate the use of the other demonstratives in writing.

\section{References}

Brown, G., \& Yule, G. (1983). Discourse Analysis. Cambridge: Cambridge University Press.

Butt, D. (2000). Using Functional Grammar. An Explorer's Guide. Sydney: National Centre for English Language Teaching and Research.

Enfield, N. J. (2003). Demonstratives in Space and Interaction. Language, 79, 82-152. http://dx.doi.org/lan.2003.0075

Grice, P. (1975). Logic and Conversation. In P. Cole, \& M. John (Eds.), Syntax and Semantics (Vol. 3, pp. 41-58). New York: Academic Press.

Grice, P. (1989). Studies in the Way of Words. Cambridge: Havard University Press.

Halliday, M. A. K., \& Hasan, R. (1976). Cohesion in English. London: Longman.

Halliday, M. A. K., \& Hasan, R. (1989). Language, Context, and Text: Aspects of Language in a Social-semiotic Perspective. Victoria: Deakin University.

Hamadi, H. M. A., \& Muhammed, B. J. (2009). Pragmatic: Grice's Conversational Maxims Violations in the Responses of Some Western Politician. Journal of the College of Arts, University of Basrah, 50, 1-23.

Himmelman, N. P. (1996). Demonstratives in Narrative Discourse: A Taxonomy of Universal Uses. In B. Fox (Ed.), Studies in Anaphora (pp. 205-254). Amsterdam and Phila delphia: John Benjamin.

Huang, Y. (2000). Discourse Anaphora: Four Theoretical Models. Journal of Pragmatics, 32, 151-176.

Leech, G. N. (1980). Exploration in Semantics and Pragmatics. Amsterdam: John Benjamins.

Levinson, S. C. (1983). Pragmatics. Cambridge: Cambridge University Press.

Mey, J. L. (2001). Pragmatics. Oxford: Blackwell.

Moreno, A. I. (2003). The Role of Cohesive Devices as Textual Constraints on Relevance. International Journal of English Studies, 3(1), 111-165.

Romer, U., \& Wuff, S. (2011). Applying Corpus Methods to Written academic texts: Explorations of MICUSP. Journal of Writing Research, 2(2), 99-127.

Rustipa, K. (2013). The Pedagogical Implications of Coherence in English Argumentative Discourse by 
Indonesian Professional. Excellence in Higher Education, 4(1), 40-52. http://dx.doi.org/105195/ehe.201380

Rustipa, K. (2014). Metadiscourse in Indonesian EFL Learners Persuasive Texts: A Case Study at English Department, UNISBANK. International Journal of English Linguistics, 4(1), 44-52. http://dx.doi.org/10.5539/ijel.v4nlp44

Storrer. (2002). Coherence in text and hypertext. Retrieved November 30, 2014, from http://www.hytex.info

Stubbs, M. (1983). Discourse Analysis. Oxford: Basil Blackwell.

Swales. (2005). Attended and Unattended this in Academic Writing: A Long and Unfinished Story. ESP Malaysia, 11, 1-15.

Yourgrau, P. (1990). Demonstratives. Oxford: Oxford University Press.

Zaki, M. (2011). The Semantics and Pragmatics of Demonstratives in English and Arabic (Doctoral dissertation). Middlesex University.

\section{Copyrights}

Copyright for this article is retained by the author(s), with first publication rights granted to the journal.

This is an open-access article distributed under the terms and conditions of the Creative Commons Attribution license (http://creativecommons.org/licenses/by/3.0/). 